\title{
Activity-Dependent Regulation of Dendritic Complexity by Semaphorin 3A through Farp1
}

\author{
(1)Lucas Cheadle ${ }^{1,2}$ and (1)Thomas Biederer ${ }^{1}$ \\ ${ }^{1}$ Department of Neuroscience, Tufts University School of Medicine, Boston, Massachusetts 02111, and 2Interdepartmental Neuroscience Program, Yale \\ University, New Haven, Connecticut 06520
}

Dendritic arbors are complex neuronal structures that receive and process synaptic inputs. One mechanism regulating dendrite differentiation is Semaphorin/Plexin signaling, specifically through binding of soluble Sema3A to Neuropilin/PlexinA coreceptors. Here we show that the protein Farp1 [FERM, RhoGEF (ARHGEF), and pleckstrin domain protein 1], a Rac1 activator previously identified as a synaptogenic signaling protein, contributes to establishing dendrite tip number and total dendritic branch length in maturing rat neurons and is sufficient to promote dendrite complexity. Aiming to define its upstream partners, our results support that Farp1 interacts with the Neuropilin-1/PlexinA1 complex and colocalizes with PlexinA1 along dendritic shafts. Functionally, Farp1 is required by Sema3A to promote dendritic arborization of hippocampal neurons, and Sema3A regulates dendritic F-actin distribution via Farp1. Unexpectedly, Sema3A also requires neuronal activity to promote dendritic complexity, presumably because silencing neurons leads to a proteasome-dependent reduction of PlexinA1 in dendrites. These results provide new insights into how activity and soluble cues cooperate to refine dendritic morphology through intracellular signaling pathways.

\section{Introduction}

The architecture of dendritic arbors determines how synaptic inputs are received and integrated. Arbor elaboration involves an early stage of dynamic dendrite elongation, branch addition, and retraction, followed by a later stage of slowed branch dynamics (Dailey and Smith, 1996; Cline and Haas, 2008). Mechanisms that regulate the development of dendritic trees include soluble cues, adhesive interactions, and neuronal activity (Wong and Ghosh, 2002; Polleux and Ghosh, 2008; Jan and Jan, 2010).

The class 3 Semaphorin Sema3A is a secreted chemotropic protein with roles in axon guidance, neuronal polarity, and dendrite development (Polleux et al., 1998; Fenstermaker et al., 2004; Morita et al., 2006; Schlomann et al., 2009; Tran et al., 2009; Shelly et al., 2011). The Sema3A receptor complex is composed of neuropilin-1 (Nrp-1), the ligand-binding subunit, and a PlexinA family member, the signal-transducing component (Takahashi et al., 1999). Sema3A remodels the neuronal cytoskeleton through the Rho family GTPase Racl as well as the actin-depolymerizing factor cofilin (Jin and Strittmatter, 1997; Västriket al., 1999; Aizawa et al., 2001). This complements the Ras GTPase activating function of the PlexinA cytoplasmic domain. Additional Sema signaling mechanisms are being elucidated.

\footnotetext{
Received Sept. 13, 2013; revised April 30, 2014; accepted May 1, 2014

Author contributions: L.C. and T.B. designed research; L.C. performed research; L.C. and T.B. analyzed data; L.C. and T.B. wrote the paper.

This work was supported by NIH Grant R01 DA018928 (to T.B.) and National Science Foundation Graduate Research Fellowship DGE-0644492 (to L.C.). We thank Drs. T. Tran and R. Giger for discussions, Y. Lei for technical assistance, and the Yale CNNR program for access to its imaging core.

The authors declare no competing financial interests.

Correspondence should be addressed to Thomas Biederer, 136 Harrison Avenue, Boston, MA 02111. E-mail: thomas.biederer@tufts.edu.

DOI:10.1523/JNEUROSCI.3950-13.2014

Copyright $\odot 2014$ the authors $\quad 0270-6474 / 14 / 347999-11 \$ 15.00 / 0$
}

The extent to which soluble cues such as Semaphorins rely on neuronal activity remains to be determined. Studies in multiple systems have demonstrated that neuronal activity plays key roles in dendritic development. In the optic tectum of Xenopus laevis, blockade of glutamatergic input or deprivation of visual experience simplifies the dendritic arbor (Sin et al., 2002; Haas et al., 2006). In vitro, blocking activity in hippocampal neurons leads to shorter branches and less complex arbors, whereas stimulating neurons can increase dendrite length and complexity ( $\mathrm{Yu}$ and Malenka, 2003; Peng et al., 2009).

Activity and soluble cues may engage distinct pathways to selectively control different aspects of outgrowth and branching, or converge on the same regulators to shape dendritic development in concert. Among Semaphorin signaling components are Farp proteins [FERM, RhoGEF (ARHGEF), and pleckstrin domain protein]. Although there are few reports on the functions of these proteins, the avian ortholog of Farp1 is known to promote outgrowth of developing motor neuron dendrites and Farp2 mediates axon guidance, both downstream of Sema/Plexin signaling (Toyofuku et al., 2005; Zhuang et al., 2009). Additionally, Farp1 regulates excitatory synapse formation and morphology, and it activates the GTPase Rac1 to promote F-actin assembly (Cheadle and Biederer, 2012).

Here we analyze dendrite development and find that Farp1 is required and sufficient to shape dendritic complexity in mammalian neurons. Farp1 interacts with the Nrp-1/PlexinA1 complex and is an obligatory signaling partner of Sema3A in promoting the arborization of hippocampal dendrites. Unexpectedly, Sema3A also requires activity to increase dendritic complexity. Consistent with this finding, the dendritic expression of its coreceptor PlexinA1 is downregulated in silenced neurons. These results reveal a Farp1-dependent signaling pathway downstream of 
Sema3A/PlexinA1 and shed light on how extrinsic molecular cues can converge with intrinsic activity-dependent mechanisms to pattern dendritic arbors.

\section{Materials and Methods}

Antibodies and constructs. A polyclonal antibody (GP22) was raised in guinea pig against the peptide CSRAHILSHKESHLY, which corresponds to the extreme carboxyl-terminal sequence of rat Farp1 with an aminoterminal cysteine for coupling to beads. The serum was affinity purified and used in immunoblotting at 1:1000, in immunostaining at 1:100, and in immunoprecipitation at 1:100. Unlike the antibody YU891 we previously raised against this Farp1 epitope in rabbits (Cheadle and Biederer, 2012), purified GP22 is suitable for immunostaining of the endogenous protein as validated by staining neurons in which Farp1 had been knocked down (see Fig. 3B). YU891 was only used in this study to perform Farp1 immunoblotting in Figure $3 F$ (1:500). A polyclonal rabbit antibody that recognizes the Sema domain of rat and mouse PlexinA1 was used at 1:1000 in blotting and 1:200 in staining (PP1301, ECM Biosciences; RRID: AB_2299835). Specificity in immunoblotting was confirmed by detecting PlexinAl heterologously expressed in COS7 cells, and specificity in immunostaining of dissociated hippocampal neurons was shown by loss of signal after peptide block (peptide PP1305, $1 \mu \mathrm{g} / \mathrm{ml}$, ECM Biosciences; data not shown). Other antibodies used in this study were raised in chicken against SynCAM 1 (monoclonal clone 3E1, CM004-3, blot 1:500, MBL Laboratories; RRID: AB_592783), c-myc (ET-MY100, stain 1:200, Aves; RRID: AB_2313514), and MAP2 (AB364, Millipore; RRID: AB_571049); an antibody raised in rabbit against PSD-95 (a gift from Dr. T. C. Südhof (Stanford University, Palo Alto, CA); L667, blot 1:2000; Irie et al., 1997); a mouse monoclonal antibody against actin (clone C4, 69100, blot 1:4000, MP Biomedicals; AB_367251); and a mouse monoclonal antibody against GAPDH (clone 6c5, ab8245, blot 1:10,000; Abcam; AB_2107448).

Expression vectors included pCAGGS-BGHpA GFP-Farp1 (Cheadle and Biederer, 2012), pCAGGS mCherry (Stagi et al., 2010), and pCS2 UtrCH-Cherry encoding a fusion protein of the Utrophin Calponin Homology domain that serves as the F-actin-binding probe and was a gift from Dr. Bill Bement (University of Wisconsin-Madison, Madison, WI; Burkel et al., 2007). pcDNA3.1 myc-PlexinA1, pcDNA3.1 myc-PlexinA4, and pSec Nrp-1-HA were gifts from Dr. Elke Stein (Biomedical Associates, San Francisco, CA). Additionally, a short-hairpin construct expressed from a pGENECLIP-GFP vector that targets rat and mouse Farp1 orthologs (shFarp1) and coexpresses soluble GFP was used with a scrambled control hairpin (shScramble) construct and a shFarp1-resistant Farp1 rescue construct (Farp1 ${ }^{\text {sh resist; }}$; Cheadle and Biederer, 2012).

Cell culture. HEK293 cells from ATCC were cultured using standard conditions and transfected using X-treme GENE 9 (Roche Applied Science). HEK293 cells were treated with Sema3A (1.14 nM; catalog \#5926S3-025, carrier free, R\&D Systems) for $20 \mathrm{~h}$ before fixation. For imaging, cells were plated onto coverslips at $30,000 \mathrm{cells} / \mathrm{ml}$.

Primary hippocampal neurons were prepared from rats as described previously (Biederer and Scheiffele, 2007), and dissociated cells were plated on Matrigel (BD Biosciences). At 5-7 d in vitro (d.i.v.), neurons were transfected using Lipofectamine LTX and PLUS reagent (Invitrogen). For pharmacological treatments, tetrodotoxin (TTX; $1 \mu \mathrm{M}$, Tocris Bioscience) and picrotoxin (PTX; $100 \mu \mathrm{M}$, Tocris Bioscience) were added to neurons at 14 d.i.v., and neurons were processed after $7 \mathrm{~d}$ of chronic treatment. Where indicated, neurons were treated with purified Sema3A $(1.14 \mathrm{~nm})$ for $20 \mathrm{~h}$ before fixation. The concentration was chosen because it induces Sema3A-dependent dendrite branching (Morita et al., 2006). Treatment with leupeptin (200 $\mu \mathrm{M} ; \mathrm{AB} 01108$, American Bioanalytical) and MG132 (10 $\mu \mathrm{M}$; 474790, EMD Millipore) was performed $2 \mathrm{~h}$ before fixation as described previously (Ehlers, 2003; Jacob et al., 2012).

Biochemistry. To investigate the expression of proteins in cultured neurons, neurons were lysed on ice in HEPES (25 mM), $\mathrm{pH} 7.4, \mathrm{MgCl}_{2}$ (10 mM), and Triton X-100 (1\%) with PMSF (0.5 mM). Samples were cleared by spinning at $20,800 \times g$ for $15 \mathrm{~min}$ at $4^{\circ} \mathrm{C}$ and denatured with $2 \%$ SDS. Immunoprecipitation was performed from total forebrain homogenates of rats at 3 weeks of age. Brain tissue was homogenized on ice
A
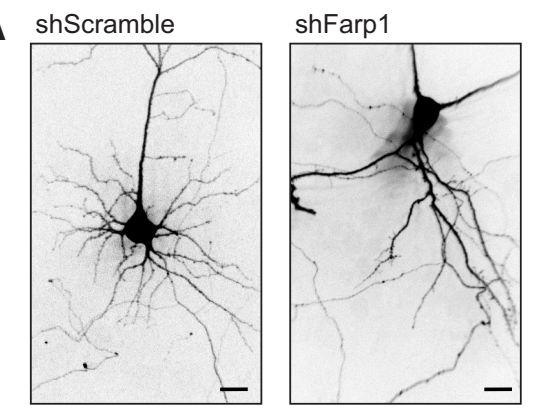

shFarp1 + rescue

B

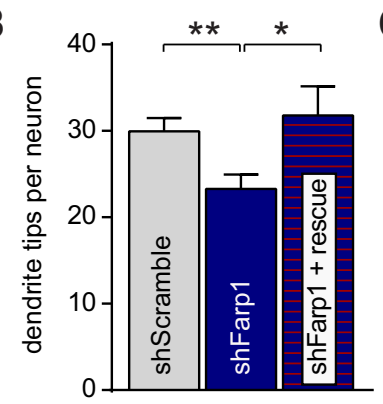

C

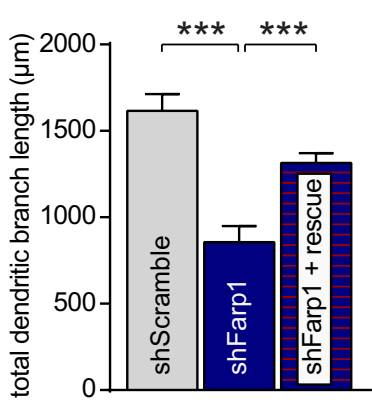

D

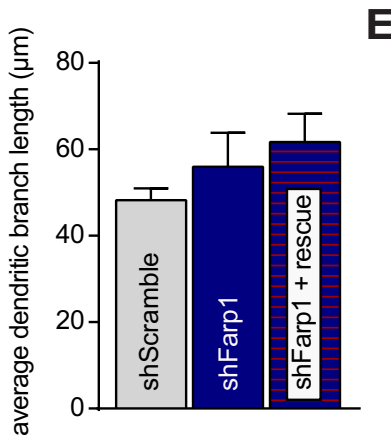

E

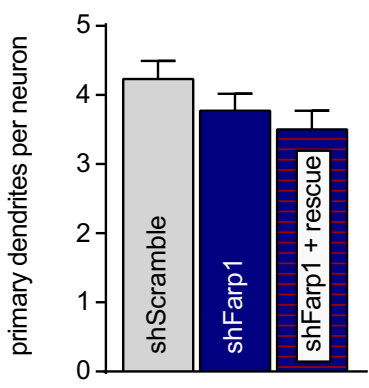

Figure 1. Farp1 is required for increased dendritic complexity in maturing neurons. $A, \mathrm{Im}$ ages of dissociated hippocampal neurons at 21 d.i.v. expressing GFP (grayscale) from shScramble control or shFarp1 knockdown vectors, or shFarp1 with the rescue construct Farp $1^{\text {sh resist }}$. Scale bars, $15 \mu \mathrm{m}$. B. Farp1 was necessary for the high dendritic complexity at 21 d.i.v. as shown by quantification of dendrite tip number per neuron from images as in $A$. The reduction in tip number was rescued by knockdown-resistant Farp1. shScramble, 37 neurons; shFarp1, 33; shFarp1 plus Farp1 ${ }^{\text {sh resist }}$, 19. Data are from three independent experiments. $C$, TDBL was lowered by knockdown of Farp1. shScramble, 19 neurons; shFarp1, 12; shFarp1 plus Farp $1^{\text {sh resist }}, 10$. Data are from three independent experiments. $D$, No change in ADBL of neurons after Farp1 knockdown. shScramble, 16 neurons; shFarp1, 10; shFarp1 plus Farp1 ${ }^{\text {sh resist }}$, 10. Data are from three independent experiments. $\boldsymbol{E}$, Farp1 had no effect on the number of primary dendrites. ShScramble, 26 neurons; shFarp1, 22; shFarp1 plus Farp1 ${ }^{\text {sh resist }}$, 15. Data are from three independent experiments. ${ }^{*} p<0.05 ;{ }^{* *} p<0.01 ;{ }^{* * *} p<0.001$.

in HEPES (25 mM), pH 7.4, and sucrose (320 mm) with protease inhibitors, cleared by centrifugation at $800 \times g$ for $10 \mathrm{~min}$ at $4^{\circ} \mathrm{C}$, and extracted by Triton X-100 (1\%) with $\mathrm{NaCl}$ added $(50 \mathrm{~mm})$. After centrifugation, the brain extract was precleared by rotating with G-protein beads (Invitrogen) for $1 \mathrm{~h}$ at $4^{\circ} \mathrm{C}$. Purified Farpl antibody GP2 2 was then added to the precleared detergent extracts $(1: 100)$ and rotated for $2.5 \mathrm{~h}$ at $4^{\circ} \mathrm{C}$, followed by the addition of G-protein beads for $1 \mathrm{~h}$. Beads were washed with extraction buffer and eluted with $2 \%$ SDS. Western blotting was performed using standard procedures, and proteins were either detected by chemiluminescence or quantified using infrared dye-conjugated secondary antibodies with an Odyssey Imaging System (Li-Cor).

Immunocytochemistry. Immunocytochemistry was performed on cultured hippocampal neurons at 21 d.i.v. and on HEK293 cells. After washing with PBS, cells were fixed with $4 \%$ paraformaldehyde and $4 \%$ sucrose for $15 \mathrm{~min}$ at room temperature. Cells were washed again and blocked and permeabilized in PBS adjusted to 3\% FBS and 0.1\% Triton X-100. Cells were incubated with primary antibodies in blocking buffer over- 
A
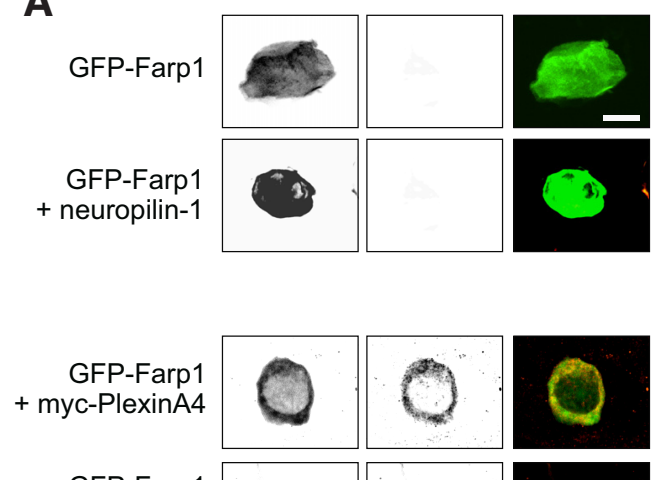

+ myc-PlexinA4

+ neuropilin-1

GFP-Farp1

+ myc-PlexinA4

+ neuropilin-1
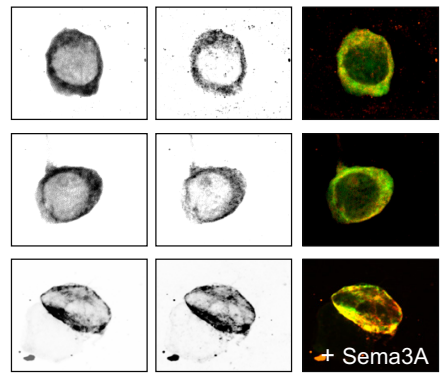

GFP-Farp
+ myc-PlexinA
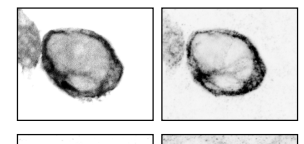

GFP-Farp1

+ myc-PlexinA1

+ neuropilin-1

GFP-Farp1

+ myc-PlexinA1

+ neuropilin-1

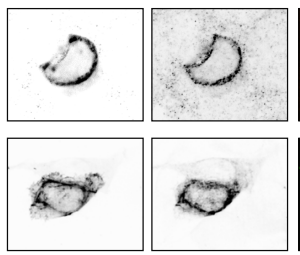

GFP-Farp1 myc-Plexin
B

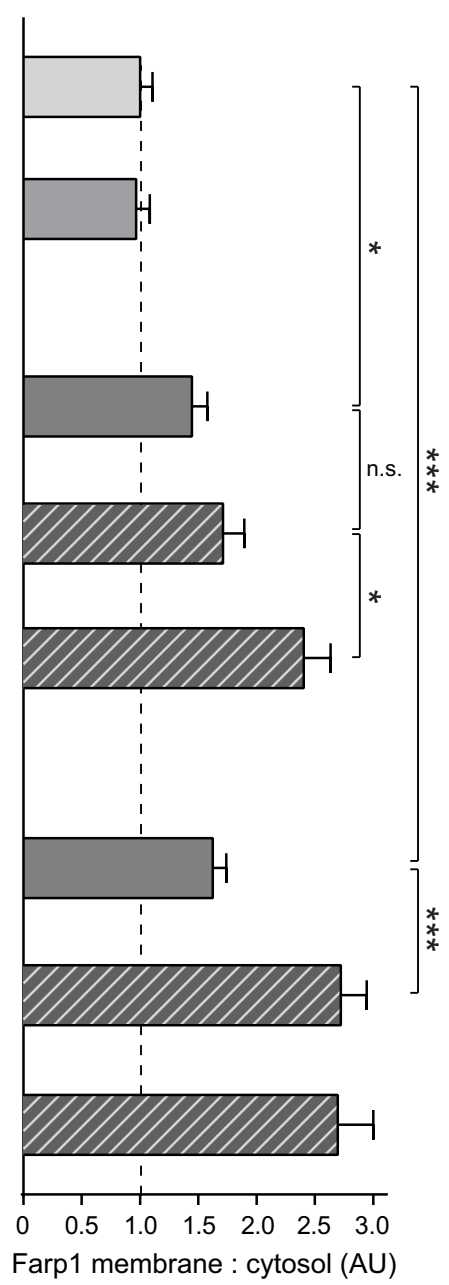

using Volocity (PerkinElmer). Dendritic shaft fluorescence intensities of UtrCH-Cherry were measured as average fluorescence intensity in ROIs of $\sim 2 \times 2 \mu \mathrm{m}$ in three adjacent areas within $3 \mu \mathrm{m}$ of each other, and measurements were additionally obtained from a spine head within $4 \mu \mathrm{m}$ of these dendritic areas. This allowed for quantitative analysis of the ratio of $\mathrm{F}$-actin in dendrites versus spines. Colocalization of Farp1 and PlexinA1 staining in neurons was measured in ImageJ by calculating intensity correlation quotients to determine whether the intensity variance of fluorescent signals changes in dependence on one another, with values between 0 and 0.5 indicating significant colocalization. As a measure independent of changes in pixel mean intensities, we calculated the Pearson coefficient, with values $0-1$ corresponding to greater levels of colocalization.

Analyses of dendritic complexity were performed using ImageJ. Full dendritic arbors were assembled by tiling images (see Fig. $7 A$ for examples). The ImageJ cell counter plugin was used to mark and count dendrite tips and primary dendrites, and dendritic branches were traced in Image J using the segmented line tool. Average dendritic branch length (ADBL) represents the average of the lengths of all dendrites except primary dendrites, whereas total dendritic branch length (TDBL) is the sum of the length of all dendrites including primaries. Primary dendrite lengths are excluded from the ADBL measurement because they are much longer than secondary and tertiary dendrites and their lengths are highly variable across neurons. Increases in tip number and TDBL are reflective of higher dendrite complexity and/or segment length (Uylings et al., 1986). Spine density measurements were performed using ImageJ as described previously (Cheadle and Biederer, 2012).

Data and statistical analysis. All quantitated analyses were performed with the researcher blind to the conditions. Data analysis was performed using GraphPad Prism 5 (GraphPad Software). Statistical analyses were performed as indicated using either the Student's $t$ test with errors corresponding to the SEM or ANOVA.

Animal procedures. All animal procedures undertaken in this study were approved by the Institutional Animal Care and Use Committee

night at $4^{\circ} \mathrm{C}$ and secondary Alexa Fluor dye-conjugated antibodies (Invitrogen) for $90 \mathrm{~min}$ at $4^{\circ} \mathrm{C}$. Cells were washed and mounted on glass coverslips in Vectashield medium (Vector Laboratories).

Microscopy and analysis. In most cases, imaging was performed on a PerkinElmer UltraView VoX Spinning Disk microscope equipped with a Hamamatsu C9100-50 camera and a Nikon Perfect Focus autofocus system. Fluorochromes imaged include GFP (488 nm), mCherry (568 nm), and Alexa 647 (Invitrogen). Images were acquired with either a Nikon $60 \times$ oil Plan Apochromat VC objective with 1.4 numerical aperture or a Nikon $40 \times$ oil CFI Plan Apo with 1.0 numerical aperture. Images in Figure 3, $B, D$, and $E$ were obtained on a Zeiss LSM710 confocal microscope equipped with a Lasos argon laser (Lasertechnik) and acquired in Zen 2010 software. Images were acquired using a Zeiss $63 \times$ oil plan Apochromat objective with 1.4 numerical aperture. Care was taken to use the same acquisition settings for every condition.

Fluorescence intensity measurements along dendrites as well as linescan analyses of protein distribution in HEK293 cells were performed and were in compliance with NIH guidelines.

\section{Results}

The cytoskeletal regulator Farp1 is required for the high complexity of maturing dendrites

To investigate whether Farpl can regulate dendritic complexity in hippocampal neurons, we knocked down Farp1 expression in cultured neurons at 7 d.i.v. and analyzed their dendritic arbors at 21 d.i.v. Dendritic arborization was assessed by measuring the number of dendrite tips per neuron, total dendritic branch length (TDBL), and average dendritic branch length (ADBL) (Fig. 1A). Images were tiled in all morphometric analyses of this study to display the full dendritic arbor of transfected neurons for quantification (see Fig. $7 A$ for examples). We measured that knockdown of Farp1 reduces dendrite tip number in these 
maturing neurons (shScramble, $30.0 \pm$ 1.5 vs shFarp1, $23.3 \pm 1.7 ; p=0.005$; Fig. $1 B)$. This knockdown effect was rescued by expression of a knockdown-resistant Farp $1^{\text {sh resist }}$ variant (shFarp1 plus Farp $\left.1^{\text {sh resist }}, 31.8 \pm 3.4 ; p=0.015\right)$, confirming that the effect is specific. TDBL was also significantly decreased after Farp1 knockdown (shScramble, $1615 \pm$ $98 \mu \mathrm{m}$; shFarp1, $856 \pm 96 ; p<0.0001$; Fig. $1 C$ ) and could be mostly rescued by Farp1 $1^{\text {sh resist }}$ (shFarp1 plus Farp1 ${ }^{\text {sh resist }}$, $1315 \pm 57 ; p<0.001)$. Although both a decrease in TDBL and dendritic tip number can result from a reduction in dendritic branching, these two parameters of dendritic complexity are not necessarily correlated (Rajan and Cline, 1998). There was no significant change in ADBL or the number of primary dendrites (Fig. $1 D, E$ ). Our data support that Farp1 shapes dendritic complexity in maturing neurons.

Farp1 is recruited to membranes by the Neuropilin-1/PlexinA1 receptor complex Considering the roles of Semaphorin signaling in regulating dendrite complexity, we next analyzed whether members of the PlexinA family and Farp1 interact. We expressed GFP-Farp1 alone, with mycepitope-tagged PlexinA4 or PlexinA1, or together with the coreceptor Nrp-1 in HEK293 cells and quantified the fluorescence ratio of GFP-Farp1 in the membrane versus the cytosol (Fig. 2). Coexpression of Nrp-1 alone with GFP-Farp1 did not affect the extent of Farp1 membrane localization, whereas expression of PlexinA4 or PlexinA1 increased the fraction of membrane-bound Farp1 significantly by $44 \pm 13 \%(p=0.017)$ and $63 \pm 11 \%(p<$ $0.001)$, respectively. No difference in expression levels of myctagged PlexinA4 and PlexinA1 was apparent after immunostaining for myc. Coexpression of Nrp-1 with PlexinA4 did not significantly alter the amount of Farp 1 at the membrane, whereas coexpression of Nrp-1 with PlexinA1 further increased the membrane-localized fraction of Farp1 to $172 \pm 22 \%(p<$ 0.0001). We next treated HEK293 cells coexpressing Farp1 with PlexinA1 and Nrp-1, or PlexinA4 and Nrp-1, with soluble Sema3A to analyze whether extracellular ligand binding to Nrp1/PlexinA complexes affects intracellular Farp1 localization. Sema3A treatment had no effect on the already strong Farp1 membrane recruitment in cells coexpressing PlexinA1 and Nrp-1, and this high Farp1 fraction at membranes was also reached in cells expressing PlexinA4 and Nrp-1 if they were treated with Sema3A. These findings support that Farp1 is recruited to membranes by Nrp-1/PlexinA complexes.

\section{Farp1 and PlexinA1 colocalize along dendrites and interact in} the brain

To investigate the localization of Farp 1 in neurons, we raised and purified an antibody against the extreme $\mathrm{C}$ terminus of the protein that detects the endogenous protein in immunoblotting and immunostaining applications (Fig. $3 A, B$ ). Analyzing the expression profile of Farp1 and PlexinA1, we found that both are ex-
B
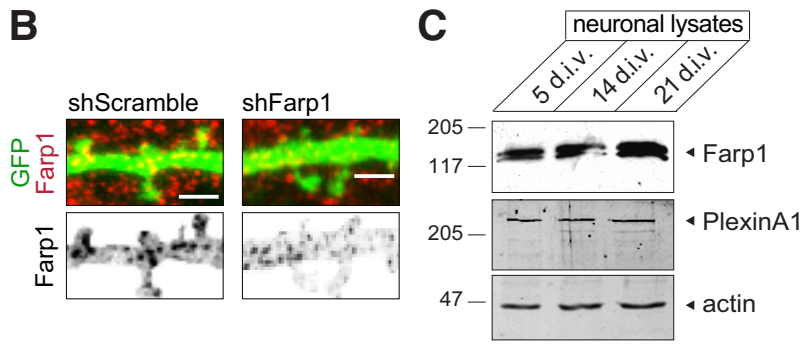

$\mathrm{E}$
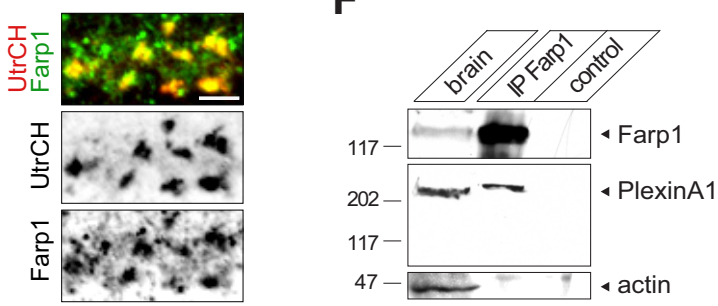

Figure 3. Endogenous Farp1 is expressed in dendrites and spines, colocalizes with PlexinA1 along dendrites, and interacts with (14, and 21 d.i.v. probed as indicated for Farp1, PlexinA1, and actin as the loading control. Equal amounts of cipitation. PlexinA1 was detected in Farp1 immunoprecipitates but not in controls. Actin served as
lane contains $1.5 \%$ of the brain extract amount used to obtain each loaded immunoprecipitate.

pressed in cultured hippocampal neurons at 5 d.i.v. when dendrites start to differentiate and remain expressed when dendrites become mature at 21 d.i.v. (Fig. 3C). We costained dissociated hippocampal neurons at 21 d.i.v. for Farp1 and PlexinA1 and found Farp1 in clusters along dendritic shafts positive for MAP2 (Fig. 3D). Similarly, PlexinA1 appeared in clusters along dendritic shafts at 21 d.i.v. While some PlexinAl appeared in Farp1-negative puncta near dendritic shafts, Farp1 and PlexinA1 mostly overlapped within dendritic shafts. An intensity correlation quotient of $0.22 \pm 0.01$ and a Pearson coefficient of $0.90 \pm$ 0.007 supported their strong colocalization ( $n=23$ neurons). Endogenous Farp1 was also detected in dendritic spines, the postsynaptic specializations of excitatory synapses, which were positive for the F-actin probe UtrCH-Cherry (Fig. 3E). This localization is consistent with our previous analysis of epitopetagged Farp1, which localizes to dendrites and spines but is not detectable in axons (Cheadle and Biederer, 2012). Coimmunoprecipitation of PlexinA1 with Farp1 from rat forebrain supported their biochemical interaction (Fig. $3 F$ ).

\section{Semaphorin $3 \mathrm{~A}$ requires Farp1 to increase dendritic complexity}

Sema3A has important roles in dendritic differentiation and growth during development and promotes complexity, similar to our observations for Farp1 (Polleux et al., 2000; Fenstermaker et al., 2004; Morita et al., 2006; Shelly et al., 2011). To investigate a functional relationship between Sema3A signaling and the Nrp1/PlexinA1 partner Farp1, we treated neurons at 20 d.i.v. with soluble, purified Sema3A (1.14 nM) for $20 \mathrm{~h}$ and analyzed their 
A

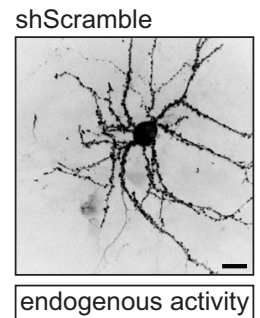

B

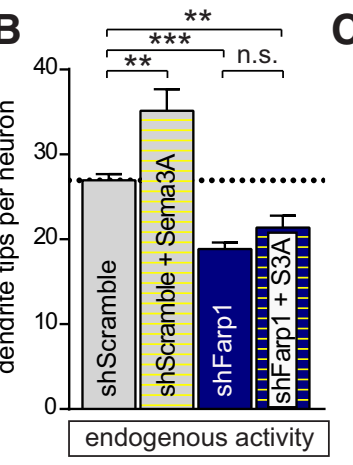

shFarp1

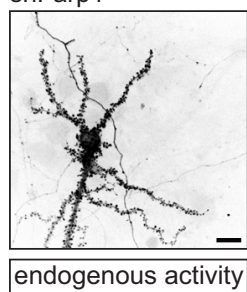

shFarp1 + Sema3A

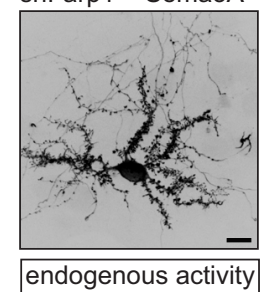

C

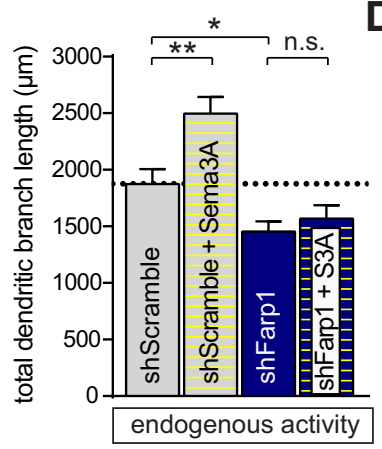

D

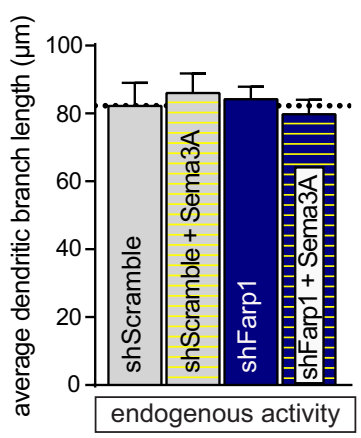

E

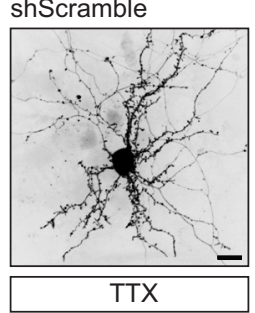

$\mathbf{F}$

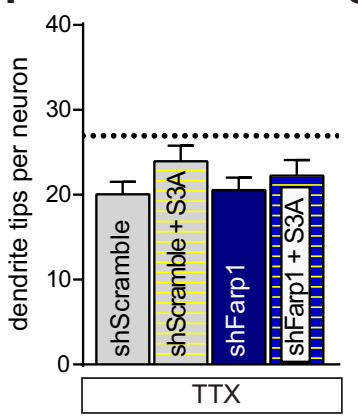

shScramble + Sema3A

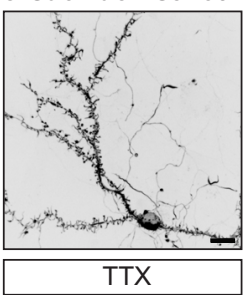

G

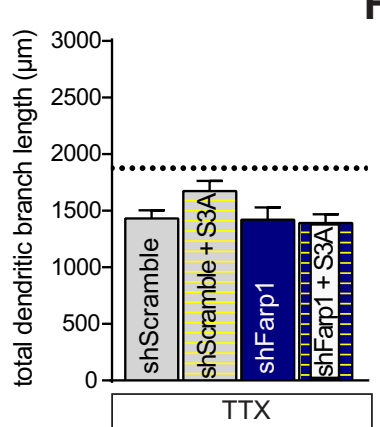

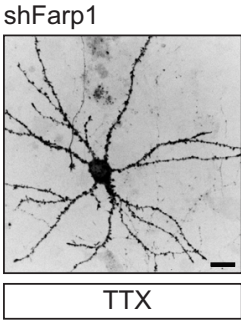

shFarp1 + Sema3A

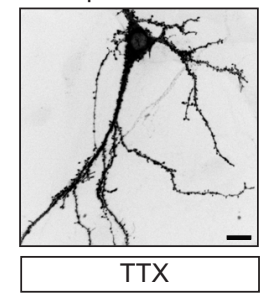

$\mathrm{H}$

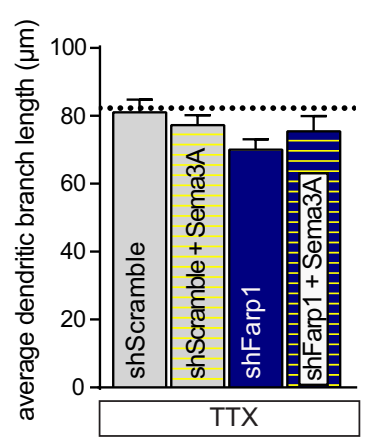

Figure 4. Semaphorin 3 A requires Farp1 and neuronal activity to promote dendritic complexity. $\boldsymbol{A}$, Grayscale images of GFP from neurons at 21 d.i.v. expressing shScramble control or shFarp1 knockdown vectors, after treatment with either purified Sema3A (1.14 nm) or vehicle control for $20 \mathrm{~h}$. Scale bars, $15 \mu \mathrm{m}$. $\boldsymbol{B}$, Quantification of dendrite tips from images as in $\boldsymbol{A}$ showed that Sema3A treatment further increases dendritic complexity under control conditions in maturing neurons, but not when Farp 1 is knocked down. shScramble, 17 neurons; shScramble plus Sema3A, 15; shFarp1, 18; shFarp1 plus Sema3A, 19. Data are from three independent experiments. $\boldsymbol{C}$, Analysis of TDBL of neurons imaged as in $\boldsymbol{A}$ supported a requirement for Farp1 in dendrite branching downstream of Sema3A. shScramble, 23 neurons; shScramble plus Sema3A, 19; shFarp1, 23; shFarp1 plus Sema3A, 24. Data are from three independent experiments. $D$, Measurement of ADBL showed no effect of Sema3A addition or Farp1 knockdown. shScramble, 18 neurons; shScramble plus Sema3A, 15; shFarp1, 18; shFarp1 plus Sema3A, 19. Data are from three independent experiments. Dotted lines in $\boldsymbol{B}-\boldsymbol{D}$ mark values from respective control conditions. $\boldsymbol{E}$, Grayscale images of GFP from neurons imaged at 21 d.i.v. as in $\boldsymbol{A}$ after chronic $7 \mathrm{~d}$ treatment with TTX to silence activity. Scale bars, $15 \mu \mathrm{m}$. $\boldsymbol{F}, \boldsymbol{G}$, No changes in dendritic complexity occurred after Sema3A addition in the presence of TTX as measured by tip number $(\boldsymbol{F})$ and TDBL $(\boldsymbol{G})$, supporting that Sema $3 A$ requires activity to promote branching. Dotted lines mark values from respective control conditions at an endogenous activity level in $\boldsymbol{B}-\boldsymbol{D}$. Tip number data are as follows: shScramble, 16 neurons; shScramble plus Sema3A, 16; shFarp1, 13; shFarp1 plus Sema3A, 15. TDBL data are as follows: shScramble, 20; shScramble plus Sema3A, 19; shFarp1, 17; shFarp1 plus Sema3A, 20. Data are from three independent experiments. $\boldsymbol{H}$, No difference in ADBL resulted from Sema3A addition or Farp1 knockdown in TTX, as at endogenous activity in $\boldsymbol{D}$. shScramble, 16 neurons; shScramble plus Sema3A, 16; shFarp1, 14; shFarp1 plus Sema3A, 15. Data are from three independent experiments. ${ }^{*} p<0.05$; ${ }^{* *} p<0.01$; ${ }^{* *} p<0.001$.

dendritic arbors as described above. Sema3A application resulted in an expected increase in arbor complexity (Fig. $4 A-C)$. Specifically, neurons treated with Sema3A and expressing the control vector shScramble had $30 \pm 9 \%(p=0.003)$ more dendrite tips than untreated neurons (shScramble, $26.9 \pm 0.8$; shScramble plus Sema3A, $35.1 \pm 2.5$; $p=0.003$; Fig. $4 B)$. Knockdown of Farp1 decreased tip number compared with control, as expected. Importantly, neurons in which Farp1 had been knocked down and were treated with Sema3A did not exhibit an increase in dendritic complexity (shFarp1, $18.8 \pm 0.8$; shFarp1 plus Sema3A, $21.4 \pm$ 1.4 tips; $p<0.0001$ and $p=0.002$ relative to shScramble, respectively; Fig. $4 B$ ). TDBL was similarly affected (shScramble, $1875 \pm 132 \mu \mathrm{m} ;$ shScramble plus Sema3A, $2496 \pm$ 147; shFarp1, $1454 \pm$ 89; shFarp1 plus Sema3A, $1570 \pm 116 ; p=$ 0.003, $p=0.01$, and $p=0.09$ relative to shScramble, respectively; Fig. 4C). No other alterations in arbor shape were observed, and ADBL was unchanged for all conditions (shScramble, $86 \pm 5.7 \mu \mathrm{m}$; shScramble plus Sema3A, $82 \pm 6.8$; shFarp1, $84 \pm 3.7$; shFarp1 plus Sema3A, $80 \pm 4.2$; Fig. $4 D$ ). These data support that Sema3A signaling requires Farp1 to promote dendritic branching in maturing neurons.

\section{Activity is required for Sema3A- dependent dendritic shaping}

Neuronal activity is critical for the establishment and refinement of dendritic arbors both in vivo and in vitro (Rajan and Cline, 1998; Yu and Malenka, 2003). However, little is known about how soluble cues and activity are integrated to shape dendritic complexity. We therefore asked whether Sema3A requires neuronal activity to increase dendritic arborization.

Chronic activity blockade with TTX in hippocampal cultures at 21 d.i.v. simplified dendritic arbors as expected (Chen and Ghosh, 2005), and neurons treated with TTX had $25 \pm 6.0 \%$ fewer dendrite tips and $24 \pm 8.4 \%$ lower TDBL than untreated controls $(p=0.0002$ and 0.0074 , respectively; Fig. $4 A, E$ and $B, C, F, G$, first columns). Notably, blocking action potentials with TTX abrogated the ability of Sema3A to increase dendritic complexity as determined by measuring tip number and TDBL (Fig. 4F, G, first vs second column). Knocking down Farp1 did not further reduce dendrite complexity under this condition. As observed at endogenous activity levels, ADBL was unchanged by Sema3A (Fig. 4H). These 
results support that neuronal activity is required for Sema3A-dependent dendrite development.

\section{Dendritic F-actin distribution is regulated by Sema3A via Farp1}

Our previous study supported that Farp1 regulates excitatory synapse number by activating the Rho family GTPase Rac1 to control F-actin assembly in spines (Cheadle and Biederer, 2012). Since changes in dendritic branching can correlate with altered actin assembly (Rocca et al., 2008), we hypothesized that Farp1 may control the distribution of F-actin in developing dendrites during Sema3A-induced dendritic branching. Neurons were transfected to coexpress the F-actin probe UtrCH-Cherry with the shFarp1 knockdown vector or shScramble control (Fig. $5 A$ ), and the fluorescence intensity of this actin marker was quantified in dendritic shafts and adjacent spines. Interestingly, Sema3A treatment significantly increased the ratio of $\mathrm{F}$-actin in the shaft versus spines by $49 \pm 13 \%(p<0.0001$; Fig. $5 B)$, suggesting roles in modulating actin assembly. This effect of Sema3A on F-actin distribution in dendrites required Farp1. Knocking down Farp1 decreased spine numbers by half (Cheadle and Biederer, 2012; and data not shown) but had no significant effect on the distribution of F-actin between dendrites and the remaining spines. This indicates that Sema3A signaling engages Farp1 to remodel the dendritic cytoskeleton.

Activity regulates PlexinA1 expression in a pathway involving proteasomal degradation

Why does Sema3A require neurons to be active to increase dendritic branching? Using immunoblotting, we first tested whether alterations in neuronal activity affect the expression of proteins within the Semaphorin signaling pathway. Unexpectedly, lysates of neurons treated chronically with TTX $(1 \mu \mathrm{M})$ contained no detectable PlexinA1 protein, whereas treatment with the GABA blocker PTX $(100 \mu \mathrm{M})$ that results in overexcitation did not alter PlexinA1 amounts (Fig. 6A). Farp1, SynCAM 1, actin, and GAPDH exhibited no changes in expression, whereas PSD-95 levels showed an apparent decrease after PTX and an increase after TTX in our culture system, consistent with lowered and elevated spine numbers, respectively (see Cherry-expressing control neurons in Fig. 7 E,F).

We hypothesized that protein degradation pathways contribute to the decrease of PlexinA1 in absence of activity. To test this, we treated neuronal cultures with TTX or vehicle for $7 \mathrm{~d}$ as above and then with the lysosomal peptidase inhibitor leupeptin (200 $\mu \mathrm{M})$ or the proteasome inhibitor MG132 (10 $\mu \mathrm{M})$ for $2 \mathrm{~h}$ before fixation. Using quantitative immunostaining, we found that neither leupeptin nor MG132 affected baseline levels of PlexinA1 in neurons (Fig. 6B, C; and data not shown). Consistent with the immunoblotting results, immunostaining revealed a strong decrease in PlexinA1 intensity by $60 \pm 11 \%(p<0.0001)$ after TTX treatment (Fig. 6C). Leupeptin did not affect the TTX-induced decrease in PlexinA1 ( $53 \pm 9 \% ; p<0.0001)$. Interestingly, treatment with the proteasomal inhibitor MG132 prevented an effect of TTX on PlexinA1 levels. Although protein degradation does
B

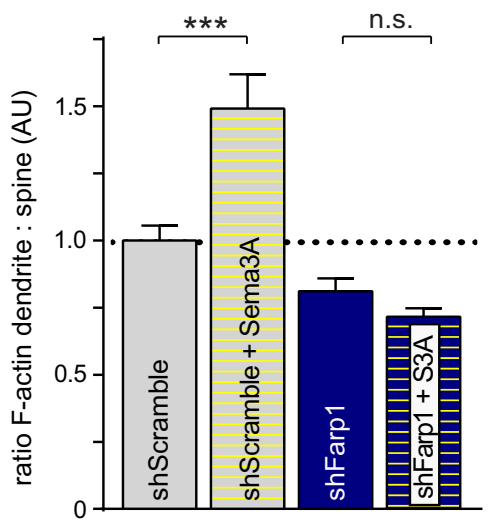

not appear to significantly control PlexinA1 levels when neuronal activity is normal, our data support that the proteasome pathway contributes to the reduction in PlexinA1 that results from activity blockade.

We next asked whether neuronal inactivation reduces dendritic development via lowering PlexinA1, or whether the reduction in PlexinA1 is only correlated with a block of activity. To address this, we overexpressed PlexinA1 and analyzed dendrites under control conditions and after TTX treatment. Neurons were either sparsely transfected with the F-actin marker UtrCHCherry alone to mark neurites or cotransfected to express both UtrCH-Cherry and myc-tagged PlexinA1. Coimmunostaining for PlexinA1 and myc confirmed that transfected, myc-positive neurons expressed higher levels of total PlexinA1 than untransfected cells (data not shown). As expected, treatment with TTX reduced TDBL (no treatment, $1598 \pm 95.7 \mu \mathrm{m}$; TTX, $1111 \pm 134$ $\mu \mathrm{m} ; p<0.05$; Fig. $6 D, E)$. Overexpression of myc-PlexinA1 in neurons was sufficient to increase TDBL in the absence of treatment (PlexinA1, $2208 \pm 192 \mu \mathrm{m} ; p<0.0001)$. Interestingly, elevated PlexinA1 also counteracted the effect of TTX on TDBL (PlexinA1 plus TTX, $1863 \pm 202 \mu \mathrm{m} ; p<0.0001$ ). ADBL was unaffected by overexpression of PlexinA1 (Fig. $6 F$ ). These results support a role for PlexinA1 in the regulation of dendritic development and indicate that an activity block affects dendrite complexity, at least in part, through downregulating dendritic PlexinA1. This reduction in PlexinA1 may underlie the inability of Sema3A to increase dendritic complexity in the absence of activity.

\section{Farp1 promotes dendritic complexity and spine numbers} even in the absence of activity

Our findings that endogenous Farp1 contributes to making dendritic arbors complex and that Sema3A requires Farp1 to acutely promote this complexity supported a role for Farp1 as a downstream signaling component of the Semaphorin/Plexin pathway. We next asked whether Farpl is sufficient to promote dendritic complexity and whether it, like Sema3A, requires activity to do 

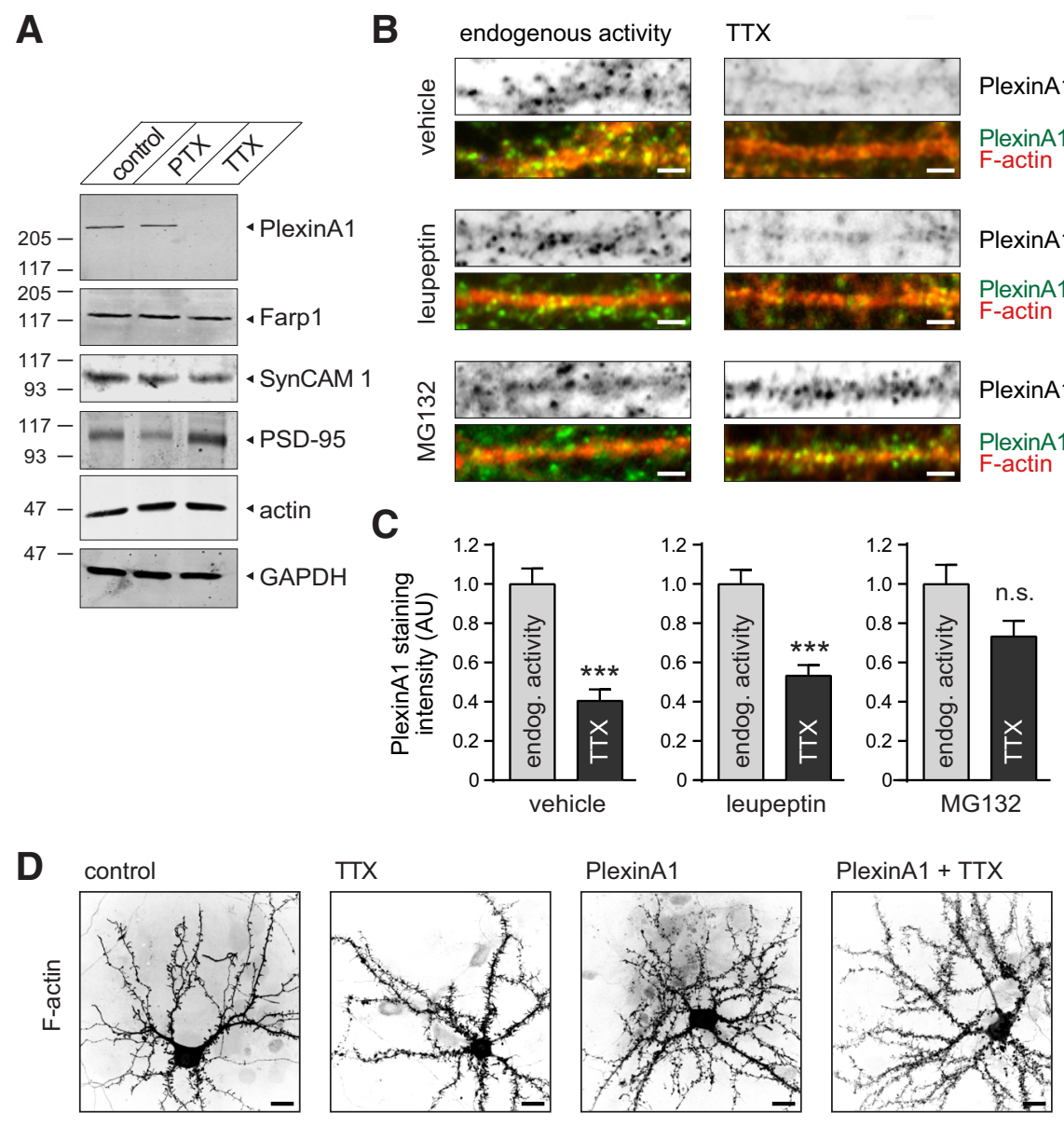

E

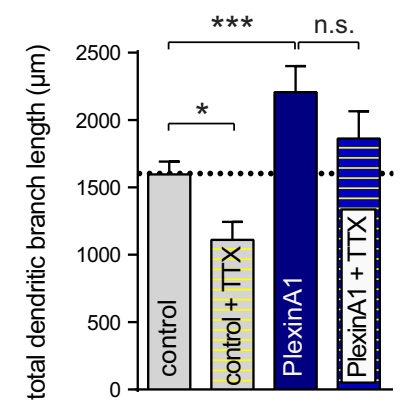

$\mathbf{F}$

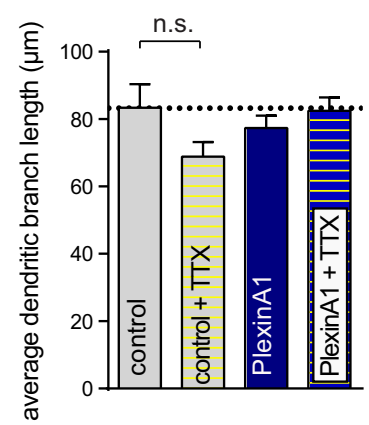

Figure 6. Neuronal inactivity decreases PlexinA1 expression. $\boldsymbol{A}$, Immunoblot of total cell lysates prepared at 21 d.i.v. from hippocampal neurons cultured under control conditions or after chronic $7 \mathrm{~d}$ treatment with PTX or TTX. Equal protein amounts of 30 $\mu \mathrm{g}$ were loaded. Immunoblotting for PlexinA1 revealed a strong reduction in total protein expression after TTX treatment. Levels of Farp1, SynCAM 1, actin, and GAPDH were not notably affected. PSD-95 levels showed an apparent decrease after PTX treatment and an increase after TTX treatment. $\boldsymbol{B}, A$ strong reduction in endogenous PlexinA1 (green) after chronic TTX treatment was confirmed by immunocytochemistry of cultured hippocampal neurons at 21 d.i.v. TTX still lowered PlexinA1 if lyosomal degradation was blocked by leupeptin. No decrease in PlexinA1 protein in dendrites of silenced neurons was observed after the addition of the proteasome inhibitor MG132. Cells coexpressed UtrCH-Cherry (red) to mark F-actin. Grayscale images show PlexinA1 staining alone. Microscope settings as well as image processing and analysis were identical for all conditions. Scale bars, $5 \mu \mathrm{m}$. C, Quantification of PlexinA1 staining intensity for conditions shown in $\boldsymbol{B}$. Significance was determined by two-way ANOVA across all conditions, and error bars represent SEM. $\boldsymbol{D}-\boldsymbol{F}$, Elevating PlexinA1 counteracts the effect of TTX on dendrite development. $\boldsymbol{D}$, Images of cultured neurons expressing UtrCH-Cherry (grayscale) at 21 d.i.v. that had been treated with vehicle or TTX. Where indicated, neurons coexpressed PlexinA1. Scale bars, $15 \mu \mathrm{m}$. $\boldsymbol{E}$, Quantification of images as in $\boldsymbol{D}$ showed that elevating PlexinA1 is sufficient to promote dendrite development and that TTX treatment did not reduce TDBL in neurons overexpressing PlexinA1. $F$, ADBL was unaffected by TTX addition or PlexinA1 overexpression. ${ }^{*} p<0.05 ;{ }^{* * *} p<0.001$.

so. Cultured neurons were transfected to express soluble Cherry alone or with GFP-Farp1 and imaged at 21 d.i.v. Images were tiled to visualize full dendritic arbors using Cherry as volume marker (Fig. 7A), and dendritic morphologies were measured. At endog-
PlexinA1

PlexinA 1
F-actin

PlexinA1 F-actin

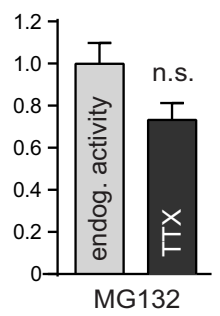

enous activity levels, the exogenous expression of Farp1 was sufficient to increase dendrite tip number (Cherry alone, $28.2 \pm 1.3$ tips; plus GFP-Farp1, $36.5 \pm 2.0 ; p<0.01$; Fig. $7 B$ ). Although PTX had no effect on the dendrites of control neurons expressing Cherry alone, neurons coexpressing Farp1 had simplified dendritic arbors under this overexcitation condition as determined by measuring dendrite tips (PTX plus GFPFarp1, $19.4 \pm 1.2 ; p<0.001$ to PTX plus Cherry). Block of action potentials by TTX reduced dendrite tip number compared with control neurons expressing Cherry (TTX, $21.9 \pm 1.9 ; p<0.05$ ). Notably, elevating Farp1 expression was sufficient in the presence of TTX to increase dendrite tip number, making neurons resistant to simplification of their dendritic arbors after inactivity (TTX plus GFPFarp1, $38.7 \pm 1.6 ; p<0.001$ compared with Cherry-expressing neurons treated with TTX or at endogenous activity). Similarly, measurements of TDBL showed that Farp1 still increased this parameter of dendrite development in silenced neurons (Fig. 7C). ADBL was not affected by Farp1 or manipulation of neuronal activity (Fig. 7D). Thus, unlike Sema3A, Farp1 does not require activity to promote dendritic complexity.

In addition to affecting the dendritic arbor, TTX increased the number of dendritic spines (Cherry alone, $7.2 \pm 0.5$ spines $/ 10 \mu \mathrm{m}$; plus TTX, $9.6 \pm 0.6$; $p<$ 0.001 ; Fig. $7 E, F)$, as reported for maturing neurons (Lauri et al., 2003; Wierenga et al., 2006). Farp1 promoted spine numbers at endogenous activity levels (Fig. $7 F$ ) as described previously (Cheadle and Biederer, 2012), while not reaching significance in the presence of PTX. Farp1 increased spine density also in the presence of TTX (TTX plus GFP-Farp1, $12.1 \pm 0.5$ spines $/ 10 \mu \mathrm{m}$ dendrite; $p<0.001$ compared with TTX plus Cherry). Both functions of Farp1 in promoting dendrite complexity and spine number therefore do not require neuronal activity, consistent with activity acting upstream of Farp1 on PlexinA1 expression.

\section{Discussion}

Here we delineate a Semaphorin-dependent signaling pathway that promotes dendritic complexity via the actin regulatory protein Farp1. Our results support that Farp1 signaling is necessary for the high extent of arborization of maturing dendrites. Aiming for mechanistic insight, we show that Farp1 is recruited to plasma membranes by the Nrp-1/PlexinA1 receptor complex and that Farp1 and PlexinA1 colocalize along dendrites 
of maturing neurons. Notably, Farp1 is an obligatory signaling partner that promotes Sema3A-dependent increases in dendrite complexity in maturing neurons, and our data support that Sema3A also modulates F-actin distribution in dendrites via Farp1. Moreover, blockade of action potentials abrogates Sema3Ainduced dendrite remodeling, concurrent with a strong reduction of the Semaphorin coreceptor PlexinA1. Elevating PlexinAl levels in neurons prevents this TTX-dependent dendritic simplification. Consistent with activity regulating steps upstream of Farp1, elevating Farp1 expression is sufficient to increase dendritic complexity even in TTX-silenced neurons. These results support a model that Nrp-1/ PlexinA1 localize Farp1 to dendrites where it acts downstream of Sema3A to promote dendritic complexity and F-actin assembly and that a reduction of the PlexinA1/Farp1 complex in dendrites limits dendrite arborization (Fig. 8).

\section{Linking Farp1 to Neuropilin/Plexin signaling}

Secreted cues provide important signals for dendrite development and include neurotrophins such as BDNF, Wnt signaling through $\beta$-catenin, Slit/Robo interactions, and Semaphorins (McAllister et al., 1997; Polleux et al., 2000; Whitford et al., 2002; Yu and Malenka, 2003; Rosso et al., 2005; Wayman et al., 2006; Rauskolb et al., 2010; de Anda et al., 2012). Specifically, Sema3A binds Nrp/PlexinA receptor complexes to control distinct aspects of dendrite development, including neuronal polarization, dendritic growth and complexity, and synapse number, in addition to its well defined roles in growth cone collapse and axon guidance (Pasterkamp, 2012; Yoshida, 2012). Several intracellular partners mediating Sema3A/ Plexin functions have been elucidated. Sema3A can cause growth cone collapse and dendrite branching through the kinases Cdk5 and Fyn (Sasaki et al., 2002; Morita et al., 2006). Activation of Cdk5 by Sema3A mediates the phosphorylation of focal adhesion kinase (FAK), and knocking down Cdk5 or FAK leads to simplified dendritic arbors as also seen in neurons lacking Neuropilins (Ng et al., 2013) and upon loss of Farp1 (this study). Given that Sema3A has several signaling partners, it was unexpected that Farp1 is required for Sema3A-mediated increases in dendrite complexity and that its knockdown is not compensated by an alternate partner. This Farp1-specific role may reflect that we analyzed dendrite arborization in maturing neurons, whereas Sema3A may guide earlier stages of dendrite development through other signaling partners. This is supported
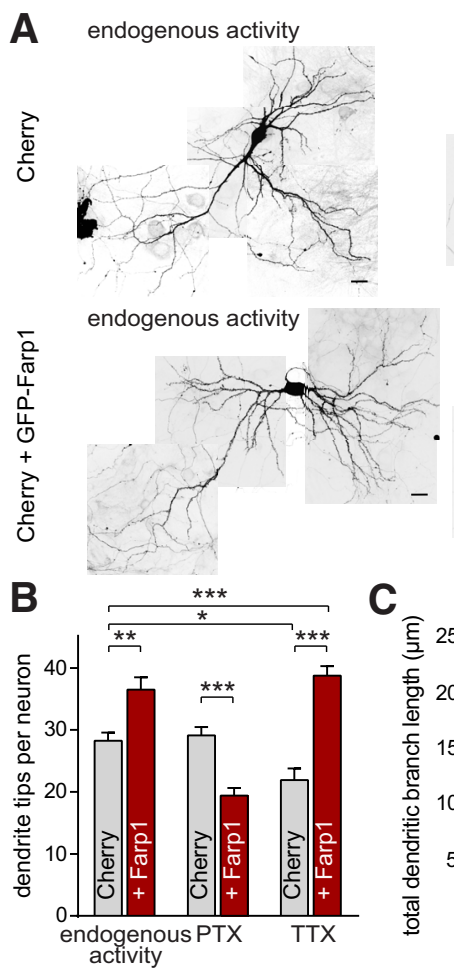

C

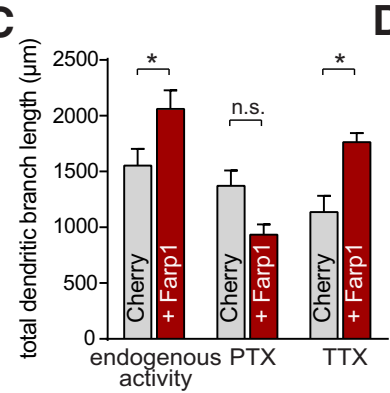

PTX
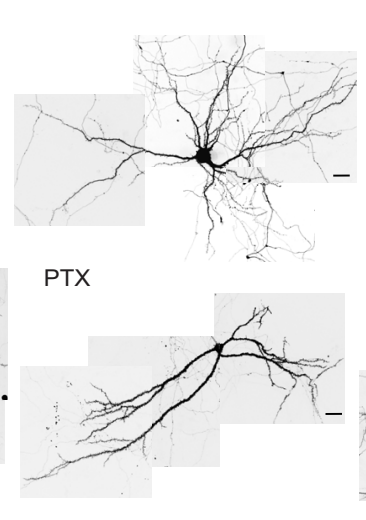

TTX

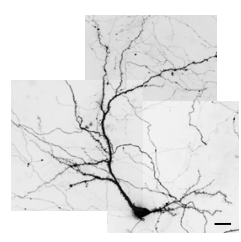

TTX

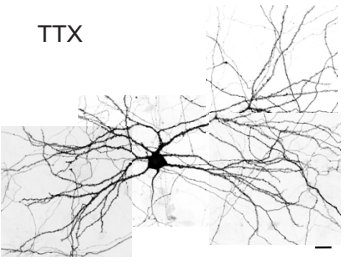

D

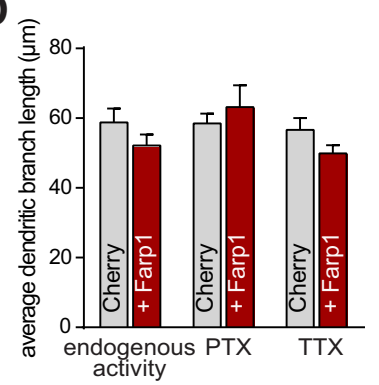

F

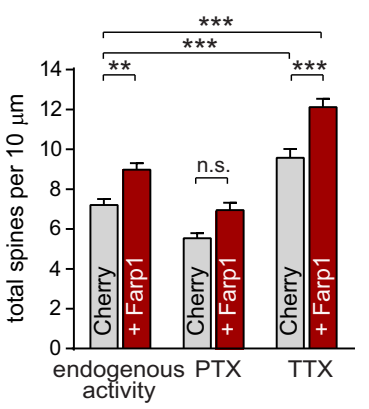

Figure 7. Farp1 is sufficient to promote dendritic complexity and spine numbers in the absence of activity. $\boldsymbol{A}$, Images of dissociated hippocampal neurons at 21 d.i.v. expressing soluble Cherry (gray) as the volume marker either alone (top row) or with GFP-Farp1 (bottom row). Images were tiled to show entire dendritic arbors. Scale bars, $15 \mu \mathrm{m}$. $\boldsymbol{B}$, The ability of Farp1 to increase dendritic branching persisted after activity blockade by TTX and was sensitive to overexcitation by PTX. Dendrite tips were quantified from images as in $A$. Untreated control at endogenous activity, $n=25$ neurons; untreated GFP-Farp1, 22; PTX-treated control, 25; PTX-treated GFP-Farp1, 23; TTX-treated control, 22; TTX-treated GFP-Farp1, 23. Data are from three independent experiments. C, TDBL was increased by elevated Farp 1 both at endogenous activity and in the absence of activity. $n=10$ neurons for all groups. Data are from three independent experiments. D, ADBL was unchanged by activity manipulation or elevated Farp1. Untreated control, $n=24$ neurons; untreated GFP-Farp1, 25; PTX-treated control, 25; PTX-treated GFP-Farp1, 23; TTX-treated control, 22; TTX-treated GFP-Farp1, 25. Data are from three independent experiments. $\boldsymbol{E}$, Confocal images of dendrites of neurons expressing soluble Cherry alone (red) or with GFP-Farp1 (green) at endogenous activity levels or after PTX or TTX treatment as indicated. Scale bars, $5 \mu \mathrm{m}$. $\boldsymbol{F}$, Quantification of spine densities from images as in $\boldsymbol{E}$ showed the expected increase in spine numbers after Farp1 overexpression under untreated control conditions. Farp1 overexpression further increased spine numbers after TTX treatment. Untreated control, $n=83$ spines; untreated GFP-Farp1, 110; PTX-treated control, 76; PTX-treated GFP-Farp1, 77; TTX-treated control, 49; TTX-treated GFP-Farp1, 65. Data are from three independent experiments. Tw0-way ANOVA was used to determine significance for all comparisons. ${ }^{*} p<0.05$; ${ }^{* *} p<0.01$; ${ }^{* * *} p<0.001$.

by the finding that Farp1 does not reduce dendrite complexity in immature neurons (Cheadle, data not shown; Mlechkovich et al., 2014).

The finding that the binding of Farp1 to PlexinA1 but not PlexinA4 is enhanced by coexpression of Nrp-1 points to different and possibly cooperative recruitment mechanisms of Farp1. 


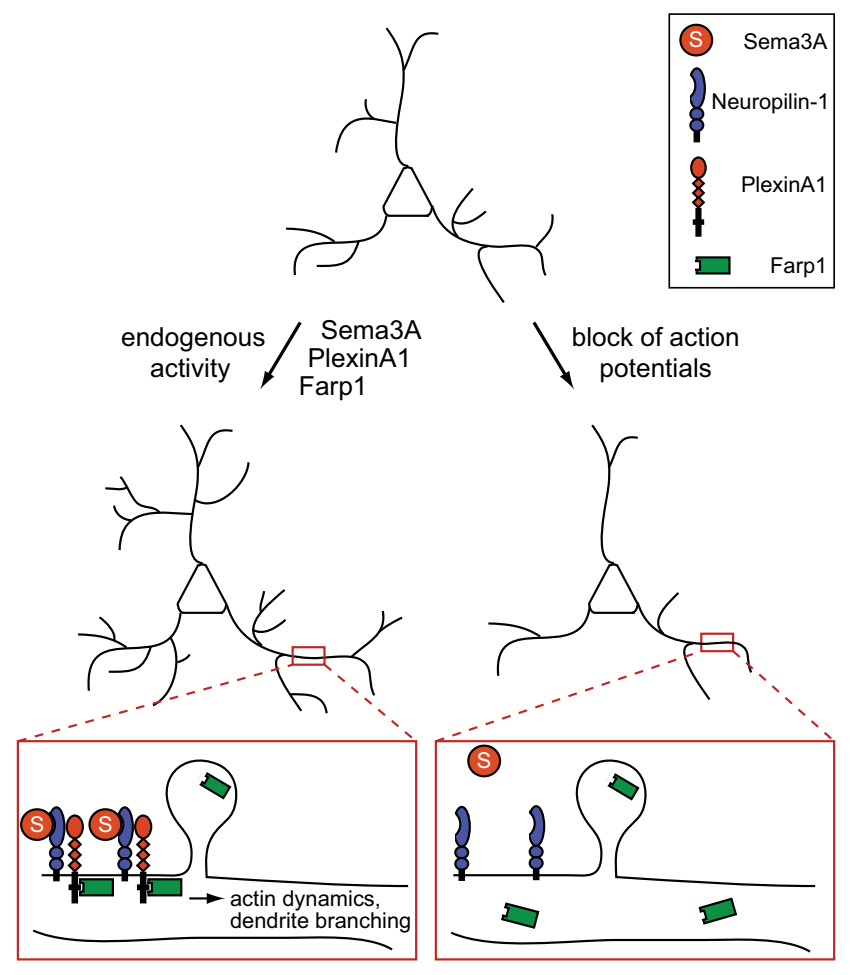

Figure 8. Model of activity-dependent Sema3A signaling through a PlexinA1/Farp1 complex to promote dendritic complexity. The model depicts how maturing neurons undergo an increase in dendritic complexity that is enhanced by Sema3A, PlexinA1, Farp1, and activity. Dendritic shaft segments with a spine are enlarged in red boxes below. Bottom left, At endogenous activity Sema $3 \mathrm{~A}$ (red circle) can bind Neuropilin-1 (blue)/PlexinA1 (red) complexes that recruit Farp1 (green) to the membrane. Farp1 is required for Sema3A-induced dendritic branching and F-actin distribution changes. Bottom right, PlexinA1 expression is strongly reduced in silenced neurons, impeding Semaphorin signaling via pathways that include Farp1.

In this study, we focused on the interaction of Farp1 with Nrp-1/ PlexinA1 as strong baseline interactions with preassembled Nrp1/PlexinA1 complexes may enable Farp1 to rapidly signal after Sema3A stimulation, and because overexpression of PlexinA1 is sufficient to promote dendritic branching. The additional Sema3A-induced recruitment of Farp1 to PlexinA4/Nrp-1/ PlexinA4 complexes suggests that Farp1 may have multiple signaling roles downstream of Sema3A that are temporally and spatially regulated, which can now be elucidated. General functions of Sema/Farp signaling in dendrite morphogenesis are conserved across species, as findings in chick motoneurons show that Farp1 promotes dendritic outgrowth stimulated by Sema6A (Zhuang et al., 2009). However, developing chick motoneurons have simple morphologies, and it could not be tested in this previous study whether Farp1 alters dendrite arborization in chick such as shown here in mammalian neurons.

\section{Remodeling of the dendritic cytoskeleton by Sema3A/Farp1 signaling}

Cytoskeletal regulators control the shape and dynamics of dendritic arbors. Sema3A can act on these regulators, and it engages, for example, LIM kinase to regulate the phosphorylation of cofilin, thereby controlling its ability to bind and depolymerize actin (Aizawa et al., 2001). In addition, several functions of Sema3A, including growth cone collapse and neuronal polarization, involve Rac1 (Västriket al., 1999; Lerman et al., 2007), a Rho family GTPase that promotes dendritic complexity and drives spine formation (Ruchhoeft et al., 1999; Li et al., 2000; Nakayama et al.,
2000; Van Aelst and Cline, 2004; Tada and Sheng, 2006; de Curtis, 2008). We previously showed that Farp1 specifically binds and activates Racl and promotes F-actin assembly (Cheadle and Biederer, 2012). In agreement with a role of Farp1 in linking Sema3A to cytoskeletal changes in dendrites, our study now provides, to our knowledge, the first description of a direct role of Sema3A in controlling dendritic F-actin in maturing neurons. While this finding does not demonstrate that Sema3A promotes dendrite complexity via increased F-actin assembly in dendritic shafts, it warrants future investigations of dendritic Rac1 signaling downstream of Sema3A/Farp1.

Sema3A shapes dendrites in dependence on neuronal activity Developing dendrites undergo rapid branch addition and retraction, followed by a less dynamic period (Dailey and Smith, 1996). These processes are tightly controlled by neuronal activity, and glutamatergic input and sensory experience are required for the proper growth of the dendritic arbor (Rajan and Cline, 1998; Sin et al., 2002; Portera-Cailliau et al., 2003). Our results now provide evidence that Sema3A requires neuronal activity to promote dendritic complexity. Our finding that TTX treatment reduces PlexinA1 protein expression via the proteasome pathway suggests that it is the loss of PlexinA1 that may render Sema3A unable to promote dendritic complexity when neurons are silenced. To our knowledge, this is the first report that PlexinA1 levels are regulated by neuronal activity. Moreover, the increased dendritic arborization after PlexinA1 overexpression at endogenous activity levels indicates that this protein is a rate-limiting factor in dendrite remodeling. The sufficiency of Farp1 to increase dendritic maturation even in silenced neurons is consistent with a role downstream of Sema3A/PlexinA1 signaling and a direct ability to regulate F-actin in dendrites. The effects of Sema3A and Farp 1 on dendrites may themselves alter neuronal activity, as the ability of dendrites to propagate action potentials is strongly influenced by the number of branch points (Vetter et al., 2001). Notably, knocking down Farp1 in the presence of TTX does not further simplify dendritic arbors. This indicates that Farp 1 does not contribute to establishing the baseline of dendrite complexity that is reached without activity-enhanced remodeling.

\section{A role for Farp1 in integrating dendrite and synapse development?}

In support of the synaptotrophic model that links dendrite development with synapse formation, blocking glutamatergic activity slows dendrite growth and retards arbor maturation (Cline and Haas, 2008). Simultaneous monitoring of both synapses and dendrites across development shows that dynamic, immature dendrites are associated with nascent, immature synapses, whereas stable dendrites contain more mature synapses (Li et al., 2011). In fact, the maturation of synapses on immature dendrites precedes dendrite stability, indicative that synapse development can instruct dendritic stabilization (Niell et al., 2004). Such coupling is reflected on the molecular level, and trans-synaptic interactions by neurexin/neuroligin complexes or EphB receptors, the Rac GEF Tiam1 that binds EphB2, and Rac1 itself can mediate both spine formation and dendrite outgrowth (Nakayama et al., 2000; Moreno-Flores et al., 2002; Tolias et al., 2007; Kayser et al., 2008; Chen et al., 2010). Corresponding signaling functions may also converge on Farp1 in dendrites of mammalian neurons. In a previous study, we identified Farpl as a binding partner of the synaptic adhesion protein SynCAM 1 in dendritic spines that promotes excitatory synapse formation (Cheadle and Biederer, 2012). This supports that Farpl acts, on the one hand, down- 
stream of Sema3A in shafts to control dendrite complexity and, on the other hand, via postsynaptic SynCAM 1 to promote excitatory synapse development. It will be important to test whether developmental alterations in the expression, localization, or function of upstream partners such as SynCAM 1 and Nrp-1/ PlexinA1 underlie the ability of Farp 1 to play different roles during neuronal differentiation, from regulating synapse formation in developing neurons to controlling dendrite complexity in maturing neurons.

\section{Future directions}

Given the diversity of dendritic arbors across neuronal cell types, it can now be elucidated to what extent Sema3A and Farp1 signaling contributes to determining the architecture of dendritic trees in different neuronal populations. Moreover, aberrations in dendritic morphology are strongly correlated with developmental and psychiatric diseases, including autism-spectrum disorders, schizophrenia, and mental retardation (Kulkarni and Firestein, 2012). Specifically, the brains of patients with mental retardation exhibit misshapen dendritic protrusions across development (Purpura, 1974), and dendritic arbors of neurons from schizophrenic patients are smaller and less complex than those of controls (Broadbelt et al., 2002). Altered Semaphorin signaling may affect neuronal differentiation in these diseases (Pasterkamp and Giger, 2009). Interestingly, a microdeletion that includes the FARP1 gene has been linked to mental retardation (Amor et al., 2005), although a role of Farp1 in human brain disorders has not yet been established. Together, our elucidation of an activity-dependent Sema3A pathway that regulates dendritic complexity via Farp1 can contribute to understanding the maturation of neuronal morphology and its disease-linked aberrations.

\section{References}

Aizawa H, Wakatsuki S, Ishii A, Moriyama K, Sasaki Y, Ohashi K, SekineAizawa Y, Sehara-Fujisawa A, Mizuno K, Goshima Y, Yahara I (2001) Phosphorylation of cofilin by LIM-kinase is necessary for semaphorin 3A-induced growth cone collapse. Nat Neurosci 4:367-373. CrossRef Medline

Amor DJ, Voullaire L, Bentley K, Savarirayan R, Choo KH (2005) Mosaic monosomy of a neocentric ring chromosome maps brachyphalangy and growth hormone deficiency to 13q31.1-13q32.3. Am J Med Genet 133A: 151-157. CrossRef Medline

Biederer T, Scheiffele P (2007) Mixed-culture assays for analyzing neuronal synapse formation. Nat Protoc 2:670-676. CrossRef Medline

Broadbelt K, Byne W, Jones LB (2002) Evidence for a decrease in basilar dendrites of pyramidal cells in schizophrenic medial prefrontal cortex. Schizophr Res 58:75-81. CrossRef Medline

Burkel BM, von Dassow G, Bement WM (2007) Versatile fluorescent probes for actin filaments based on the actin-binding domain of utrophin. Cell Motil Cytoskeleton 64:822-832. CrossRef Medline

Cheadle L, Biederer T (2012) The novel synaptogenic protein Farp1 links postsynaptic cytoskeletal dynamics and transsynaptic organization. J Cell Biol 199:985-1001. CrossRef Medline

Chen SX, Tari PK, She K, Haas K (2010) Neurexin-neuroligin cell adhesion complexes contribute to synaptotropic dendritogenesis via growth stabilization mechanisms in vivo. Neuron 67:967-983. CrossRef Medline

Chen Y, Ghosh A (2005) Regulation of dendritic development by neuronal activity. J Neurobiol 64:4-10. CrossRef Medline

Cline H, Haas K (2008) The regulation of dendritic arbor development and plasticity by glutamatergic synaptic input: a review of the synaptotrophic hypothesis. J Physiol 586:1509-1517. CrossRef Medline

Dailey ME, Smith SJ (1996) The dynamics of dendritic structure in developing hippocampal slices. J Neurosci 16:2983-2994. Medline

de Anda FC, Rosario AL, Durak O, Tran T, GräffJ, Meletis K, Rei D, Soda T, Madabhushi R, Ginty DD, Kolodkin AL, Tsai LH (2012) Autism spectrum disorder susceptibility gene TAOK2 affects basal dendrite formation in the neocortex. Nat Neurosci 15:1022-1031. CrossRef Medline de Curtis I (2008) Functions of Rac GTPases during neuronal development. Dev Neurosci 30:47-58. CrossRef Medline

Ehlers MD (2003) Activity level controls postsynaptic composition and signaling via the ubiquitin-proteasome system. Nat Neurosci 6:231-242. CrossRef Medline

Fenstermaker V, Chen Y, Ghosh A, Yuste R (2004) Regulation of dendritic length and branching by semaphorin 3A. J Neurobiol 58:403-412. CrossRef Medline

Haas K, Li J, Cline HT (2006) AMPA receptors regulate experiencedependent dendritic arbor growth in vivo. Proc Natl Acad Sci U S A 103: 12127-12131. CrossRef Medline

Irie M, Hata Y, Takeuchi M, Ichtchenko K, Toyoda A, Hirao K, Takai Y, Rosahl TW, Südhof TC (1997) Binding of neuroligins to PSD-95. Science 277:1511-1515. CrossRef Medline

Jacob TC, Michels G, Silayeva L, Haydon J, Succol F, Moss SJ (2012) Benzodiazepine treatment induces subtype-specific changes in GABA(A) receptor trafficking and decreases synaptic inhibition. Proc Natl Acad Sci U S A 109:18595-18600. CrossRef Medline

Jan YN, Jan LY (2010) Branching out: mechanisms of dendritic arborization. Nat Rev Neurosci 11:316-328. CrossRef Medline

Jin Z, Strittmatter SM (1997) Racl mediates collapsin-1-induced growth cone collapse. J Neurosci 17:6256-6263. Medline

Kayser MS, Nolt MJ, Dalva MB (2008) EphB receptors couple dendritic filopodia motility to synapse formation. Neuron 59:56-69. CrossRef Medline

Kulkarni VA, Firestein BL (2012) The dendritic tree and brain disorders. Mol Cell Neurosci 50:10-20. CrossRef Medline

Lauri SE, Lamsa K, Pavlov I, Riekki R, Johnson BE, Molnar E, Rauvala H, Taira T (2003) Activity blockade increases the number of functional synapses in the hippocampus of newborn rats. Mol Cell Neurosci 22:107117. CrossRef Medline

Lerman O, Ben-Zvi A, Yagil Z, Behar O (2007) Semaphorin3A accelerates neuronal polarity in vitro and in its absence the orientation of DRG neuronal polarity in vivo is distorted. Mol Cell Neurosci 36:222-234. CrossRef Medline

Li J, Erisir A, Cline H (2011) In vivo time-lapse imaging and serial section electron microscopy reveal developmental synaptic rearrangements. Neuron 69:273-286. CrossRef Medline

Li Z, Van Aelst L, Cline HT (2000) Rho GTPases regulate distinct aspects of dendritic arbor growth in Xenopus central neurons in vivo. Nat Neurosci 3:217-225. CrossRef Medline

McAllister AK, Katz LC, Lo DC (1997) Opposing roles for endogenous BDNF and NT-3 in regulating cortical dendritic growth. Neuron 18:767778. CrossRef Medline

Mlechkovich G, Peng SS, Shacham V, Martinez E, Gokhman I, Minis A, Tran TS, Yaron A (2014) Distinct cytoplasmic domains in Plexin-A4 mediate diverse responses to Semaphorin $3 \mathrm{~A}$ in developing mammalian neurons. Sci Signal 7:ra24. CrossRef Medline

Moreno-Flores MT, Martín-Aparicio E, Avila J, Díaz-Nido J, Wandosell F (2002) Ephrin-B1 promotes dendrite outgrowth on cerebellar granule neurons. Mol Cell Neurosci 20:429-446. CrossRef Medline

Morita A, Yamashita N, Sasaki Y, Uchida Y, Nakajima O, Nakamura F, Yagi T, Taniguchi M, Usui H, Katoh-Semba R, Takei K, Goshima Y (2006) Regulation of dendritic branching and spine maturation by semaphorin $3 \mathrm{~A}-$ Fyn signaling. J Neurosci 26:2971-2980. CrossRef Medline

Nakayama AY, Harms MB, Luo L (2000) Small GTPases Rac and Rho in the maintenance of dendritic spines and branches in hippocampal pyramidal neurons. J Neurosci 20:5329-5338. Medline

Ng T, Ryu JR, Sohn JH, Tan T, Song H, Ming GL, Goh EL (2013) Class 3 semaphorin mediates dendrite growth in adult newborn neurons through Cdk5/FAK pathway. PloS One 8:e65572. CrossRef Medline

Niell CM, Meyer MP, Smith SJ (2004) In vivo imaging of synapse formation on a growing dendritic arbor. Nat Neurosci 7:254-260. CrossRef Medline

Pasterkamp RJ (2012) Getting neural circuits into shape with semaphorins. Nat Rev Neurosci 13:605-618. CrossRef Medline

Pasterkamp RJ, Giger RJ (2009) Semaphorin function in neural plasticity and disease. Curr Opin Neurobiol 19:263-274. CrossRef Medline

Peng YR, He S, Marie H, Zeng SY, Ma J, Tan ZJ, Lee SY, Malenka RC, Yu X (2009) Coordinated changes in dendritic arborization and synaptic strength during neural circuit development. Neuron 61:71-84. CrossRef Medline 
Polleux F, Ghosh A (2008) Molecular determinants of dendrite and spine development. Oxford: Oxford UP.

Polleux F, Giger RJ, Ginty DD, Kolodkin AL, Ghosh A (1998) Patterning of cortical efferent projections by semaphorin-neuropilin interactions. Science 282:1904-1906. CrossRef Medline

Polleux F, Morrow T, Ghosh A (2000) Semaphorin 3A is a chemoattractant for cortical apical dendrites. Nature 404:567-573. CrossRef Medline

Portera-Cailliau C, Pan DT, Yuste R (2003) Activity-regulated dynamic behavior of early dendritic protrusions: evidence for different types of dendritic filopodia. J Neurosci 23:7129-7142. Medline

Purpura DP (1974) Dendritic spine "dysgenesis" and mental retardation. Science 186:1126-1128. CrossRef Medline

Rajan I, Cline HT (1998) Glutamate receptor activity is required for normal development of tectal cell dendrites in vivo. J Neurosci 18:7836-7846. Medline

Rauskolb S, Zagrebelsky M, Dreznjak A, Deogracias R, Matsumoto T, Wiese S, Erne B, Sendtner M, Schaeren-Wiemers N, Korte M, Barde YA (2010) Global deprivation of brain-derived neurotrophic factor in the CNS reveals an area-specific requirement for dendritic growth. J Neurosci 30: 1739-1749. CrossRef Medline

Rocca DL, Martin S, Jenkins EL, Hanley JG (2008) Inhibition of Arp2/3mediated actin polymerization by PICK1 regulates neuronal morphology and AMPA receptor endocytosis. Nat Cell Biol 10:259-271. CrossRef Medline

Rosso SB, Sussman D, Wynshaw-Boris A, Salinas PC (2005) Wnt signaling through Dishevelled, Rac and JNK regulates dendritic development. Nat Neurosci 8:34-42. CrossRef Medline

Ruchhoeft ML, Ohnuma S, McNeill L, Holt CE, Harris WA (1999) The neuronal architecture of Xenopus retinal ganglion cells is sculpted by rhofamily GTPases in vivo. J Neurosci 19:8454-8463. Medline

Sasaki Y, Cheng C, Uchida Y, Nakajima O, Ohshima T, Yagi T, Taniguchi M, Nakayama T, Kishida R, Kudo Y, Ohno S, Nakamura F, Goshima Y (2002) Fyn and Cdk5 mediate semaphorin-3A signaling, which is involved in regulation of dendrite orientation in cerebral cortex. Neuron 35:907-920. CrossRef Medline

Schlomann U, Schwamborn JC, Müller M, Fässler R, Püschel AW (2009) The stimulation of dendrite growth by Sema3A requires integrin engagement and focal adhesion kinase. J Cell Sci 122:2034-2042. CrossRef Medline

Shelly M, Cancedda L, Lim BK, Popescu AT, Cheng PL, Gao H, Poo MM (2011) Semaphorin3A regulates neuronal polarization by suppressing axon formation and promoting dendrite growth. Neuron 71:433-446. CrossRef Medline

Sin WC, Haas K, Ruthazer ES, Cline HT (2002) Dendrite growth increased by visual activity requires NMDA receptor and Rho GTPases. Nature 419:475-480. CrossRef Medline

Stagi M, Fogel AI, Biederer T (2010) SynCAM 1 participates in axodendritic contact assembly and shapes neuronal growth cones. Proc Natl Acad Sci U S A 107:7568-7573. CrossRef Medline
Tada T, Sheng M (2006) Molecular mechanisms of dendritic spine morphogenesis. Curr Opin Neurobiol 16:95-101. CrossRef Medline

Takahashi T, Fournier A, Nakamura F, Wang LH, Murakami Y, Kalb RG, Fujisawa H, Strittmatter SM (1999) Plexin-neuropilin-1 complexes form functional semaphorin-3A receptors. Cell 99:59-69. CrossRef Medline

Tolias KF, Bikoff JB, Kane CG, Tolias CS, Hu L, Greenberg ME (2007) The Racl guanine nucleotide exchange factor Tiam 1 mediates EphB receptordependent dendritic spine development. Proc Natl Acad Sci U S A 104: 7265-7270. CrossRef Medline

Toyofuku T, Yoshida J, Sugimoto T, Zhang H, Kumanogoh A, Hori M, Kikutani H (2005) FARP2 triggers signals for Sema3A-mediated axonal repulsion. Nat Neurosci 8:1712-1719. CrossRef Medline

Tran TS, Rubio ME, Clem RL, Johnson D, Case L, Tessier-Lavigne M, Huganir RL, Ginty DD, Kolodkin AL (2009) Secreted semaphorins control spine distribution and morphogenesis in the postnatal CNS. Nature 462:1065-1069. CrossRef Medline

Uylings HB, Ruiz-Marcos A, van Pelt J (1986) The metric analysis of threedimensional dendritic tree patterns: a methodological review. J Neurosci Methods 18:127-151. CrossRef Medline

Van Aelst L, Cline HT (2004) Rho GTPases and activity-dependent dendrite development. Curr Opin Neurobiol 14:297-304. CrossRef Medline

Västrik I, Eickholt BJ, Walsh FS, Ridley A, Doherty P (1999) Sema3Ainduced growth-cone collapse is mediated by Racl amino acids 17-32. Curr Biol 9:991-998. CrossRef Medline

Vetter P, Roth A, Häusser M (2001) Propagation of action potentials in dendrites depends on dendritic morphology. J Neurophysiol 85:926-937. Medline

Wayman GA, Impey S, Marks D, Saneyoshi T, Grant WF, Derkach V, Soderling TR (2006) Activity-dependent dendritic arborization mediated by CaM-kinase I activation and enhanced CREB-dependent transcription of Wnt-2. Neuron 50:897-909. CrossRef Medline

Whitford KL, Marillat V, Stein E, Goodman CS, Tessier-Lavigne M, Chédotal A, Ghosh A (2002) Regulation of cortical dendrite development by SlitRobo interactions. Neuron 33:47-61. CrossRef Medline

Wierenga CJ, Walsh MF, Turrigiano GG (2006) Temporal regulation of the expression locus of homeostatic plasticity. J Neurophysiol 96:2127-2133. CrossRef Medline

Wong RO, Ghosh A (2002) Activity-dependent regulation of dendritic growth and patterning. Nat Rev Neurosci 3:803-812. CrossRef Medline

Yoshida Y (2012) Semaphorin signaling in vertebrate neural circuit assembly. Front Mol Neurosci 5:1-16. Medline

Yu X, Malenka RC (2003) Beta-catenin is critical for dendritic morphogenesis. Nat Neurosci 6:1169-1177. CrossRef Medline

Zhuang B, Su YS, Sockanathan S (2009) FARP1 promotes the dendritic growth of spinal motor neuron subtypes through transmembrane Semaphorin6A and PlexinA4 signaling. Neuron 61:359-372. CrossRef Medline 